\title{
AVALIAÇÃO CLÍNICA, RADIOGRÁFICA E HISTOLÓGICA DA PLACA EM PONTE ASSOCIADA AO PINO INTRAMEDULAR E DA PLACA DE COMPRESSÃO DINÂMICA EM OSTEOSSÍNTESE DE FÊMUR DE COELHOS
}

\author{
Natalie Ferreira Borges ${ }^{1}$, Cleuza Maria de Faria Rezende², Rogéria Serakides², \\ Raquel Gouvea dos Santos ${ }^{3}$, Renato Cesar Sacchetto Torres ${ }^{2}$
}

\author{
1 UFRB \\ 2 UFMG \\ ${ }^{3}$ CNEN \\ Correspondência: Natalie Ferreira Borges: natalieborges@ufrb.edu.br
}

RESUMO: O objetivo deste estudo foi acompanhar por avaliação clínica, radiográfica e histológica o efeito da fixação óssea com placa de compressão dinâmica (PCD) e placa em ponte (PP) associada ao pino intramedular. Foram empregados 14 coelhos da raça Nova Zelândia, quatro meses de idade, massa corporal média de 3,5 quilos. Estes foram divididos aleatoriamente em dois grupos (I e II). Todos os coelhos foram submetidos à osteotomia transversal no terço médio do fêmur direito. Nos animais do grupo I foi feita a fixação da osteotomia com PP associada ao pino intramedular, introduzidos pela técnica da mínima invasão e nos animais do grupo II utilizou-se PCD, via abordagem convencional. A técnica para colocação da PP associada ao pino intramedular permitiu alinhamento dos fragmentos e preservação das partes moles com fixação nas extremidades ósseas. Resultados positivos também foram observados nos animais submetidos a fixação da osteotomia com a PCD que propiciou fixação estável e imediata deambulação. Ao exame radiográfico, verificouse consolidação em ambos os grupos com precocidade do processo na fixação com a PCD (grupo II). Na análise histológica aos 90 dias após a colocação dos implantes observou-se no grupo I, predomínio de tecido ósseo trabecular enquanto que no grupo II havia ausência de calo ósseo e da linha de fratura, pouca quantidade de tecido ósseo trabecular e grande quantidade de tecido ósseo osteônico com características idênticas ao tecido ósseo original. Concluiu-se que as duas modalidades de fixação conduzem à consolidação dentro do período previsto, mas a fixação com PCD promove maturação precoce do processo em relação a PP e no período avaliado, não provocou alteração da constituição óssea, revelando-se um excelente método de fixação óssea.

Palavras-chave: coelho; ortopedia; placa de compressão dinâmica; placa em ponte

\section{CLINICAL, RADIOGRAPHIC AND HISTOLOGICAL EVALUATION OF THE BRIDGE PLATE ASSOCIATED WITH INTRAMEDULLARY NAILS AND DYNAMIC COMPRESSION PLATE OSTEOSYNTHESIS IN THE FEMUR OF RABBITS}

\begin{abstract}
The objective of this study was accompanied by clinical, radiographic and histological effect of bone fixation with dynamic compression plate (DCP) and bridge plate (PP) associated with intramedullary pin. We used 14 New Zealand rabbits, four months of age, mean weight of 3.5 pounds. These were divided randomly into two groups (I and II). All rabbits underwent transverse osteotomy in the middle third of the right femur. In group I was made to fix the osteotomy with intramedullary pin associated with the PP, introduced the technique of minimally invasive and in group II was used PCD via the conventional approach. The technique for placement of PP associated with intramedullary pin and allowed alignment of the fragments with preservation of soft tissue attachment to the bone ends. Positive results were also observed in animals subjected to osteotomy fixation with PCD that provided stable fixation and immediate ambulation. The radiographic evaluation, it was found in both groups consolidation with early in the process of fixing to the PCD (II group). In histological analysis at 90 days after placement of the implants was observed in group I, a predominance of trabecular bone while in group II had no callus and fracture line, a small amount of trabecular bone and a large amount of tissue bone osteônico with characteristics similar to native tissue. It was concluded that the two methods of setting lead to consolidation within the period specified, but the fixation with PCD promotes the early maturation process in relation to PP and during this period, caused no change in bone formation, revealing an excellent method of bone fixation
\end{abstract}

Key Words: rabbit; orthopedics; dynamic compression plate; bridge plate 


\section{INTRODUÇÃO}

O tratamento de fraturas tem como objetivo a consolidação óssea e o retorno precoce da função do membro e isto é possível por meio de osteossíntese estável que pode ser realizada por diferentes métodos (Piermattei, et al., 2006). Contudo é crescente a busca pelo aperfeiçoamento dos métodos de tratamento de fraturas, preferencialmente por técnicas precisas e menos invasivas (Eitel et al. 1990a, 1990b; Perren, 2002), modalidade denominada tratamento "biológico" da fratura (Perren et al., 1991; Hulse e Aron, 1994; Kowalski et al., 1996; Palmer, 1999).

Entre muitas técnicas utilizadas com este objetivo tem-se a denominada técnica da Placa em ponte (PP) que permite estabilizar a fratura com mínima invasão (Osório et al., 1994). A abordagem é feita com mínima manipulação do foco de fratura, respeitando-se as partes moles e preservando a vascularização dos fragmentos, fixando-se a placa ao fragmento proximal e distal ao foco da fratura (Vasconcelos et al., 2004 ).

Embora estes conceitos já estejam em uso na rotina clínica de pequenos animais alguns questionamentos ainda persistem, como o grau de lesão provocada em relação à capacidade do tecido de se recuperar e qual o efeito da mínima invasão na circulação óssea e extra óssea em relação à abordagem convencional. Assim, o objetivo deste estudo foi avaliar clínica, radiográfica e histologicamente 0 efeito da osteossíntese biológica pelo método da PP associada ao pino intramedular e da fixação com placa de compressão dinâmica (PCD) em osteotomias experimentais no fêmur de coelhos.

\section{MATERIAL E MÉTODOS}

Foram utilizados 14 coelhos machos, de quatro meses de idade, da raça Nova Zelândia, separados aleatoriamente em dois grupos. Nos animais do Grupo I foi usada a PP associada a um pino intramedular de Steinmann e nos do Grupo II, a PCD.

Os animais não foram submetidos a jejum alimentar e hídrico pré-operatório como sugerido por Brown (1997). O protocolo pré-anestésico consistiu de sedação com cloridrato de xilazina ${ }^{1}$ $(2,5 \mathrm{mg} / \mathrm{kg})$ via intramuscular. Para indução anestésica foi utilizado propofol $^{2}(10 \mathrm{mg} / \mathrm{kg})$ por via intravenosa lenta, seguida de anestesia epidural com bupivacaína ${ }^{3} 0,5 \%(0,25 \mathrm{ml} / \mathrm{Kg})$. 0 controle da dor foi feito com cloridrato de tramadol ${ }^{4}$ na dose de $1 \mathrm{mg} / \mathrm{kg}$ por via intramuscular, 30 minutos antes da intervenção.

Para a osteotomia femoral nos animais do grupo I, foi feita uma incisão cutânea crânio-lateral de cerca de 2.0 $\mathrm{cm}$ no terço médio da coxa direita, incisão da fáscia lata, afastamento cranial do músculo vasto lateral e caudal do bíceps femoral e com mínima exposição do fêmur e secção transversal do osso com serra oscilatória $^{5}$ acoplada a furadeira ortopédica pneumática ${ }^{6}$ sob irrigação constante com solução Ringer lactato. Seguiu-se a introdução retrógrada de um pino de Steinmann de $2.0 \mathrm{~mm}$ no canal medular e após coaptação da osteotomia com auxilio de garras ósseas, procedeu-se a introdução do pino no fragmento distal, estabelecendo assim o realinhamento ósseo (fig. 1A).

\footnotetext{
${ }^{1}$ Rompum 20mg/ml- Bayer S.A

${ }^{2}$ Proporfol Fresenius 1\%

${ }^{3}$ Cloridrato de bupivacaína -Neocaína 0,5\%

${ }^{4}$ Tramal $(50 \mathrm{mg} / \mathrm{ml})$

${ }^{5}$ Serra oscilatória de Stricker-Mirtdia Ind. Com. Imp. Exp. Ltda

${ }^{6}$ Furadeira pneumática $3 \mathrm{M}^{\circledR} 0-1100 \mathrm{rpm}$
} 
Outras duas incisões de cerca de $2.0 \mathrm{~cm}$ foram feitas proximal e distal ao foco de osteotomia. A fáscia foi incisada e com auxilio de um elevador de periósteo os tecidos foram elevados do osso em proporção suficiente para passar uma placa de aço $^{7}$ (AISI 316L) de $2.0 \mathrm{~mm}$, oito orifícios de $60 \mathrm{~mm}$ de comprimento por $1 \mathrm{~mm}$ de altura. Após a pré-moldagem para adaptação à superfície femoral, a placa foi inserida pela incisão distal, deslizando-se sobre o fêmur em direção proximal até o trocanter maior, seguindo-se a fixação alternada de dois parafusos bicorticais de $2.0 \mathrm{~mm}$ de diâmetro em cada extremidade (fig. 1B). Nos animais do Grupo II, foi usada a PCD de aço AISI $316 \mathrm{~L}$ de $2.0 \mathrm{~mm}$, oito orifícios, com as mesmas dimensões da placa em ponte. A abordagem cirúrgica do fêmur direito foi ampla, realizada segundo Piermattei e Greeley (2004) (fig. 2). A fixação da PCD ao fêmur direito previamente osteotomizado seguiu as normas da AO- ASIF. Em ambos os grupos, após a fixação da osteotomia seguiu-se a síntese da fáscia lata em padrão simples contínuo com poliglecaprone $25^{8} 4.0, \quad 0$ tecido subcutâneo foi suturado da mesma forma e a dermorrafia foi feita em padrão simples separado com fio de nylon ${ }^{9} 4.0$.

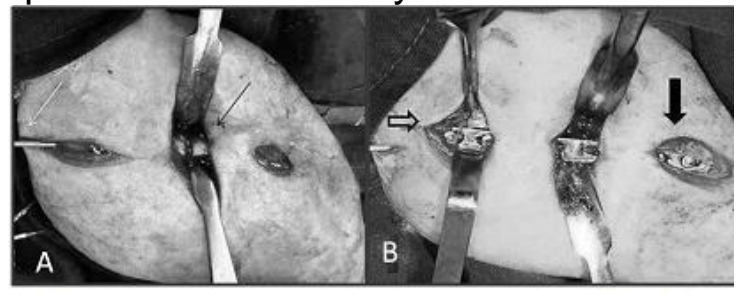

Figura 1- Imagens fotográficas do procedimento cirúrgico para colocação da placa em ponte associada ao pino intramedular (grupo l):

A) fragmentos alinhados (seta) após colocação do pino de Steinmann (seta branca)

B) placa em ponte fixada ao fêmur direito, parafusos fixados nas extremidades proximal (seta vazia) e distal (seta cheia).

Os animais foram submetidos a avaliação clínica diária por 10 dias até a retirada dos pontos e após este

\footnotetext{
${ }^{7}$ Bioconect produtos médicos e odontológicos LTDA- AISI 316L

${ }^{8}$ caprofyl 4.0-Ethicon

${ }^{9}$ Nylon 4.0-Ethicon
}

período, semanalmente até os 90 dias após cirurgias.

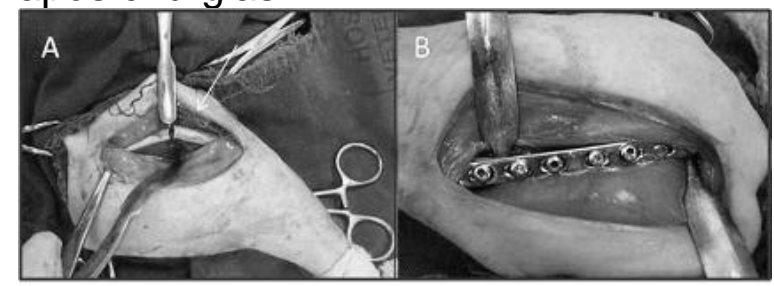

Figura 2- Imagens fotográficas do procedimento cirúrgico para colocação da placa de compressão dinâmica (grupo II):

A) osteotomia transversal realizada

B) placa de compressão dinâmica fixada ao fêmur direito.

Foram feitas radiografias nas posições médiolateral e craniocaudal de ambos os fêmures, antes das cirurgias, no pós-operatório imediato e aos 15, 30, 45, 60 e 90 dias. A avaliação radiográfica foi realizada por três avaliadores distintos e com o auxilio de um escore, foi qualificada a evolução do processo de consolidação óssea de acordo com Yuehue e Friedman (1999).

Para a análise estatística, utilizou-se a média dos valores registrados. A reação periosteal, formação de calo ósseo, formação de ponte óssea, presença de linha de osteotomia e remodelação foram os parâmetros semi-quantitativos usados para a avaliação. Os dados obtidos nos tempos 15, 30, 45, 60 e 90 dias do pós-operatório foram analisados comparando cada um dos grupos versus o controle (análise de variância ANOVA) seguido pelo teste de Log-rank com nível de significância de 5\%.

Após 90 dias de estudo, os animais foram submetidos a medicação pré-anestésica com cloridrato de xilazina na dose de $1 \mathrm{mg} / \mathrm{Kg}$, seguida de eutanásia por sobredose anestésica com tiopental sódico na dose de 90 $\mathrm{mg} / \mathrm{kg}$ por via intravenosa. O fêmur foi colhido para avaliação macroscópica e histológica. Foram avaliados a presença de calo ósseo, movimentação na linha de osteotomia, crescimento ósseo adjacente e sobre os implantes, facilidade de remoção dos implantes, aspecto do córtex ósseo sob a placa, aspecto da cápsula fibrosa que envolvia 
Avaliação clínica, radiográfica e histológica da placa em ponte associada ao pino intramedular e da placa de compressão dinâmica em osteossíntese de fêmur de coelhos

o implante, cor dos tecidos e dos implantes.

Foram colhidas amostras de osso de cerca de $2 \mathrm{~cm}$ envolvendo a região de osteotomia. As amostras foram fixadas em formol a $10 \%$ por 30 dias.

Após o período de fixação, cortes seriados do osso foram descalcificados em solução de ácido fórmico $20 \%$, tamponada com citrato de sódio e com $\mathrm{pH}$ 4,5. Uma vez descalcificadas, as amostras foram processadas como na rotina e submetidas à técnica de coloração pela hematoxilina-eosina para análise em microscópio óptico. Foi realizada análise descritiva da qualidade e maturidade do osso neoformado na região da osteotomia, considerando-se formação de calo ósseo, grau de remodelação e presença de necrose e hemorragia, dentre outros.

\section{RESULTADOS E DISCUSSÃO}

A introdução de um pino intramedular foi útil, favoreceu o alinhamento ósseo e facilitou a fixação da placa nas extremidades, além disto a associação de um pino intramedular com a placa auxilia na neutralização das forças e favorece menor manipulação dos tecidos, pois o número de parafusos na placa é reduzido. O pino intramedular permite 0 alinhamento dos fragmentos maiores sem a necessidade de manipulação dos menores, mantendo assim o potencial de cura. O pino compartilha com a placa as cargas sobre ela exercidas, reduzindo 0 estresse. Mecanicamente, o pino e a placa atuam como feixes paralelos, protegendo-se das diversas forças (Reems et al., 2003; Hulse et al., 2000; Hulse et al., 1997). Outro fator favorável da PP é a redução do contato placa/osso, minimizando assim o efeito da pressão sobre o periósteo.

A técnica para a fixação com placa em ponte é considerada relativamente simples, acessível a todo ortopedista com treinamento para osteossínteses convencionais, sem a necessidade de instrumental altamente especializado (Shimabukuro, et al., 1997; Osorio et al., 1994).

Os animais de ambos os grupos apresentaram evolução clínica sem intercorrências, não se observando quaisquer sinais de infecção ou complicação.

Por meio da avaliação radiográfica foi possível acompanhar a evolução do reparo ósseo, que ocorreu de forma satisfatória em ambos os grupos, isto foi possível graças à osteossíntese estável promovida pelos implantes (Piermattei et al., 2006), tanto na estabilização rígida alcançada nos animais do grupo II, como na fixação flexível da osteotomia com a PP associada ao pino intramedular. Além disso, nos animais do grupo I verificouse que o pino intramedular utilizado não impediu a colocação dos parafusos bicorticais, garantindo desta forma osteossíntese estável até o final do estudo como relatado por Hulse et al.(1997), (2000) e Reems et al.(2003).

$\mathrm{Na}$ tabela 1 está demonstrada a avaliação radiológica percentual comparativa entre os grupos. Aos 15 dias verificou-se na maioria dos animais do grupo I discreta a moderada (fig. 3A) reação periosteal. Neste período foi observado presença de calo ósseo discreto $(85,72 \%)$ a moderado $(14,28 \%)$. No grupo II havia reação periosteal discreta em $83,33 \%$ dos animais. O calo ósseo estava presente em grau moderado em $50 \%$, discreto (fig. $3 \mathrm{~B}$ ) em $33,33 \%$ e ausente em $16,67 \%$. 
Borges et al.. (2013)

\begin{tabular}{|c|c|c|c|c|c|}
\hline Tratamentos & $\begin{array}{c}\text { Reação } \\
\text { periosteal }\end{array}$ & $\begin{array}{c}\text { Formação } \\
\text { de ponte } \\
\text { óssea }\end{array}$ & $\begin{array}{l}\text { Linha de } \\
\text { osteotomia }\end{array}$ & $\begin{array}{c}\text { Formação } \\
\text { de calo } \\
\text { ósseo }\end{array}$ & Remodelação \\
\hline 15 dias $\mathrm{GI}$ & $\begin{array}{l}85,72 \% \mathrm{D} \\
14,28 \% \mathrm{M}\end{array}$ & $100 \% \mathrm{NU}$ & $100 \% \mathrm{AP}$ & $\begin{array}{l}85,72 \% \mathrm{D} \\
14,28 \% \mathrm{M}\end{array}$ & $100 \% \mathrm{~A}$ \\
\hline 15 dias GII & $\begin{array}{l}83,33 \% \mathrm{D} \\
16,66 \% \mathrm{M}\end{array}$ & $100 \% \mathrm{NU}$ & $100 \% \mathrm{AP}$ & $\begin{array}{l}50,00 \% \mathrm{M} \\
33,33 \% \mathrm{D} \\
16,67 \% \mathrm{~A} \\
\end{array}$ & $100 \% \mathrm{~A}$ \\
\hline 30 dias $\mathrm{Gl}$ & $\begin{array}{l}42,85 \% \mathrm{D} \\
28,57 \% \mathrm{M} \\
28,57 \% \mathrm{E}\end{array}$ & $100 \% \mathrm{NU}$ & $\begin{array}{l}85,72 \% \text { R } \\
14,28 \% \text { PD }\end{array}$ & $100 \% \mathrm{M}$ & $100 \% \mathrm{D}$ \\
\hline 30 dias GII & $\begin{array}{l}83,33 \% \mathrm{D} \\
16,66 \% \mathrm{M}\end{array}$ & $\begin{array}{l}66,66 \% \\
\text { UD } \\
33,33 \% \\
\text { UM }\end{array}$ & $\begin{array}{l}50 \% \text { R } \\
50 \% \text { PD }\end{array}$ & $\begin{array}{l}50,00 \% \mathrm{D} \\
33,33 \% \mathrm{M} \\
16,67 \% \mathrm{E}\end{array}$ & $83,3 \% \mathrm{MI}$ \\
\hline 45 dias $\mathrm{Gl}$ & $\begin{array}{l}71,42 \% \mathrm{D} \\
28,58 \% \mathrm{M}\end{array}$ & $100 \%$ UD & $\begin{array}{l}71,42 \% \text { PD } \\
28,58 \% \quad \mathrm{R}\end{array}$ & $\begin{array}{l}85,72 \% \mathrm{M} \\
14,28 \% \mathrm{D}\end{array}$ & $\begin{array}{l}16,67 \% \mathrm{D} \\
85,72 \% \mathrm{MI} \\
14,28 \% \mathrm{MA}\end{array}$ \\
\hline 45 dias GII & $\begin{array}{l}66.66 \% \text { A } \\
33,33 \% \text { D }\end{array}$ & $100 \%$ UM & $\begin{array}{l}66,66 \% \mathrm{PD} \\
33,33 \% \quad \mathrm{~A}\end{array}$ & $\begin{array}{l}66.66 \% \mathrm{D} \\
33,33 \% \mathrm{M}\end{array}$ & $100 \% \mathrm{MA}$ \\
\hline 60 dias $\mathrm{Gl}$ & $\begin{array}{l}85,72 \% \mathrm{D} \\
14,28 \% \mathrm{~A}\end{array}$ & $100 \%$ UM & 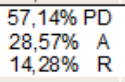 & $\begin{array}{l}57,14 \% \mathrm{D} \\
42,85 \% \mathrm{M}\end{array}$ & $\begin{array}{c}71,42 \% \mathrm{MA} \\
28,58 \% \mathrm{MI}\end{array}$ \\
\hline 60 dias GII & $100 \% \mathrm{~A}$ & $100 \%$ UC & $100 \% \quad \mathrm{~A}$ & $\begin{array}{l}83,33 \% \mathrm{~A} \\
16,66 \% \mathrm{D} \\
\end{array}$ & $100 \% \mathrm{MA}$ \\
\hline 90 dias $\mathrm{Gl}$ & $100 \% \mathrm{~A}$ & $\begin{array}{l}57,14 \% \\
\text { UM } \\
42,85 \% \\
\text { UC }\end{array}$ & $\begin{array}{l}57,14 \% \text { A } \\
42,85 \% \text { PD }\end{array}$ & $\begin{array}{l}85,72 \% \mathrm{D} \\
14,28 \% \mathrm{M}\end{array}$ & $\begin{array}{c}85,72 \% \mathrm{MA} \\
14,28 \% \mathrm{MI}\end{array}$ \\
\hline 90 dias GII & $100 \% \mathrm{~A}$ & $\begin{array}{c}100 \% \\
\text { UC }\end{array}$ & $100 \%$ & $100 \% \mathrm{~A}$ & $100 \% \quad \mathrm{MA}$ \\
\hline \multicolumn{6}{|c|}{ 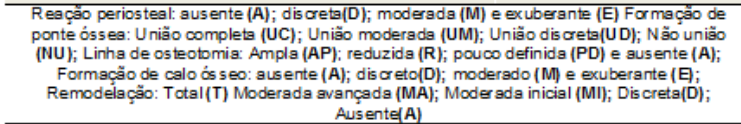 } \\
\hline
\end{tabular}

Aos trinta dias observou-se nos animais tratados com a placa em ponte, aumento do calo ósseo (fig. 4A) e reação periosteal em graus variados em todos os animais, linha de osteotomia reduzida (85,72\%). Assim como nos animais do grupo I, a reação periosteal em graus variados era presente nos coelhos do grupo II, o calo ósseo discreto em $50 \%$ dos animais, moderado em $33,33 \%$ e em um animal esta era exuberante. A linha de osteotomia encontrava-se reduzida em $50 \%$ dos animais do grupo II e pouco definida nos demais (figura 4B). Aos 45 dias já se observava redução da reação periosteal em $71,42 \%$ dos coelhos do grupo I, redução do calo ósseo, mostrando-se discreto (14,28\%) a moderado (fig. 5A) na maioria dos animais $(85,72 \%), \quad$ confirmando remodelação moderada inicial em $85,72 \%$ e moderada avançada em $14,28 \%$. A linha de osteotomia mostrava-se pouco definida em $71,42 \%$ dos animais. No grupo II o aspecto radiográfico era de consolidação mais avançada em relação aos do grupo I, pois nestes já não se via reação periosteal na maioria dos coelhos $(66,67 \%)$, o calo ósseo caracterizava-se como discreto $(66,67 \%)$ e moderado em $33,33 \%$, a ponte óssea mostrava união moderada, a linha de osteotomia era pouco definida em quatro animais $(66,67 \%)$ e já ausente (figura 5B) em dois (33,33\%), com remodelação moderada avançada em todos os animais do grupo.

Aos 60 dias nos animais do grupo I a linha de osteotomia ainda pouco definida (57,14\%) (fig. 6A) e ausente (28,57\%). Havia remodelação óssea moderada avançada $(71,42 \%)$ com calo ósseo discreto $(57,14 \%)$ a moderado $(42,85 \%)$. Neste período observou-se evolução do reparo ósseo em todos os animais de ambos os grupos, contudo nos animais do grupo II o processo de consolidação óssea mostrava-se mais evoluído, com ausência da linha de osteotomia em todos (fig. 6 B). Aos 90 dias havia diminuição do calo ósseo nos dois grupos em estudo (fig. 7) e a remodelação mostrava-se avançada. Contudo, ausência completa da linha de osteotomia foi vista em $57,14 \%$ dos animais do grupo I, fato evidente já aos 60 dias nos animais do grupo II, mostrando que a fixação com a PCD, por abordagem convencional ampla apresentou resultados superiores, comparados aos animais cuja fixação foi realizada com a PP.

A abordagem ampla com fixação de ostetomia com a PCD permitiu fixação precisa com estabilidade rígida e resultados condizentes com o citados na literatura (Uhthoff et al., 2006, Chen et al., 1966; Modabber e Jupiter, 1998). Apesar das pesquisas mais recentes indicarem que a mínima abordagem aos fragmentos fraturados e fixação flexível é mais favorável à consolidação do que a abordagem invasiva e fixação rígida, pois mantém 0 potencial de consolidação óssea (Perren, 2002; Miclau e Martin 1997; Johnson et al., 1998; Vasconcelos et al., 2004; Aron et al., 1995; Field e Törnkvist, 2001), neste estudo pode-se observar evolução da 
intramedular e da placa de compressão dinâmica em osteossíntese de fêmur de coelhos

consolidação óssea mais avançada no grupo II em relação ao grupo I. As análises estatísticas dos parâmetros radiográficos na evolução da consolidação óssea mostraram diferenças significativas apenas para o parâmetro ponte óssea, com formação de ponte óssea completa mais precoce nos animais do grupo II, no qual se utilizou a PCD. Os demais parâmetros, reação periosteal, calo ósseo, linha de osteotomia e remodelação não foram estatisticamente significativos entre os dois grupos, o que leva a dizer que ambos os métodos foram bem sucedidos.

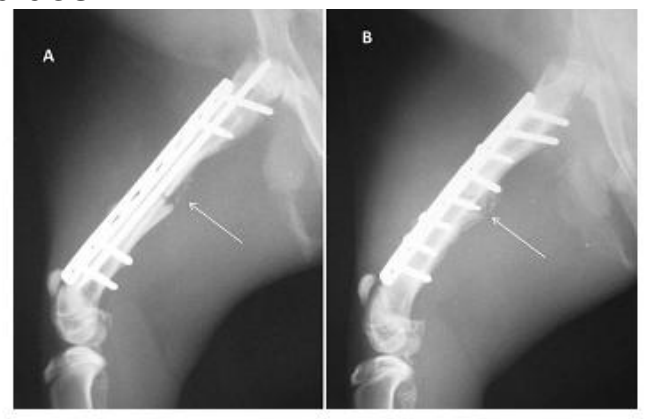

Figura 3- Imagens fotográficas de radiografias realizadas 15 dias após a intervenção cirúrgica:

A) Incidência médio-lateral do fêmur direito de coelho submetido a fixação com

placa em ponte associada ao pino intramedular (grupo I) com reação periosteal moderada (seta)

B) Incidência médio-lateral do fêmur direito de coelho submetido a fixação com

placa de compressão dinâmica (grupo II), formação de calo ósseo discreto (seta).

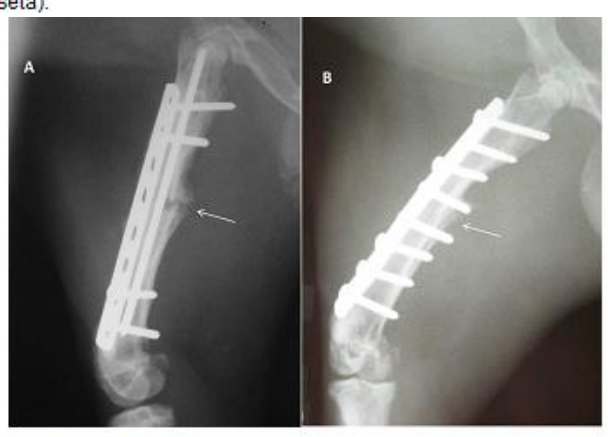

Figura 4- Imagens fotográficas de radiografias realizadas 30 dias após a intervenção cirúrgica.

A) Incidência médio-lateral do fêmur direito de coelho submetido a fixacão con placa em ponte associada ao pino intramedular (grupo I) com calo ósseo e linha de osteotomia bem definida (seta).

B) Incidência médio-tateral do fêmur direito de coelho submetido a fixação corr placa de compressão dinâmica (grupo II) com linha de osteotomia pouco definida (seta).

$\mathrm{Na}$ avaliação macroscópica após eutanásia dos animais aos 90 dias, foi observada mobilidade normal das articulações fêmoro-tíbio-patelar e coxofemoral em todos os animais, mostrando que os implantes utilizados não comprometeram a função do membro, permitiu a mobilidade do mesmo, sem interferir na função articular, requisito indispensável no tratamento de fraturas, como reiterado frequente na literatura (Chen et al., 1966; Miclau e Martin 1997; Modabber e Jupiter, 1998; Johnson et al., 1998; Aron et al., 1995; Field e Törnkvist, 2001; Perren, 2002; Vasconcelos et al., 2004; Piermatei et al., 2006; Uhthoff et al., 2006).

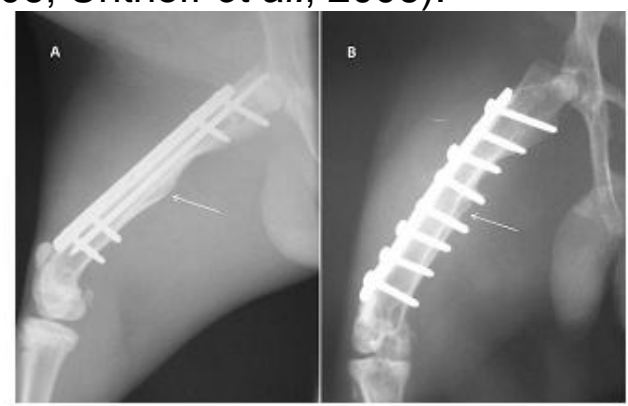

Figura 5- Imagens fotográficas de radiografias realizadas 45 dias após a intervenção cirúrgica.

A) Incidência médio-lateral do fêmur direito de coelho submetido a fixação com placa em ponte associada ao pino intramedular (grupo I) com calo ósseo discreto (seta).

B) Incidência médio-lateral do fêmur direito de coelho submetido a fixação com placa de compressão dinâmica (grupo II) com linha de osteotomia ausente (seta)

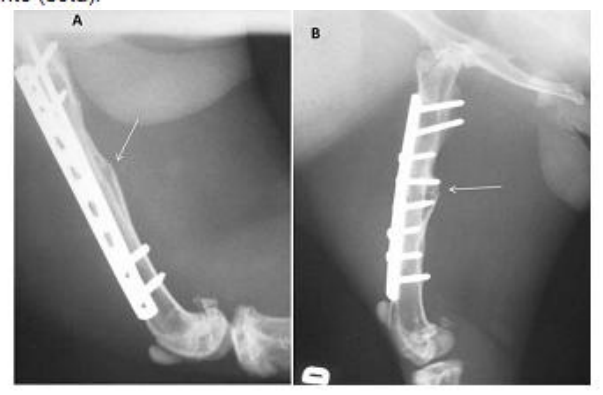

Figura 6- Imagens fotográficas de radiografias realizadas 60 dias após a intervenção cirúrgica.

A) Incidência médio-lăteral do fêmur direito de coelho submetido a fixação com placa em ponte associada ao pino intramedular (grupo I) com calo ósseo discreto, remodelação moderada avançada e linha de osteotomia pouco definida (seta).

B) Incidência médio-lateral do fêmur direito de coelho submetido a fixação com placa de compressão dinâmica (grupo II) com linha de osteotomia ausente

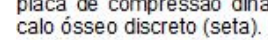

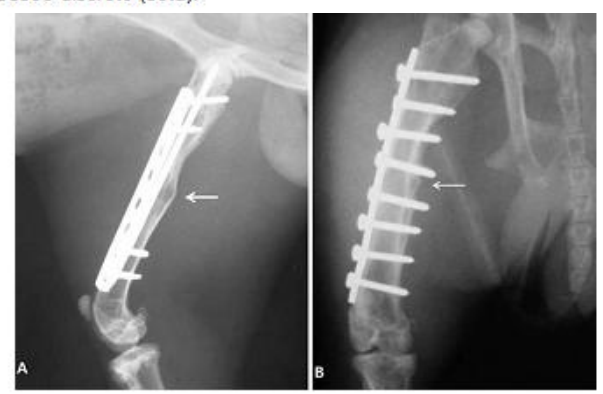

Figura 7- Imagens fotográficas de radiografias realizadas 90 dias após a intervenção cirúrgica.

A) Incidência médio-lăteral do fêmur direito de coelho submetido a fixação com placa em ponte associada ao pino intramedular (grupo I), calo ósseo discreto, remodelação moderada avançada, linha de osteotomia ausente (seta).

B) Incidência médio-lateral do fêmur direito de coelho submetido a fixação com placa de compressão dinâmica (grupo II), linha de osteotomia ausente, calo ósseo ausente, remodelação moderada avançada (seta). 
Em todos verificou-se a impressão da placa sobre o osso (figura 8) mais evidente naqueles do grupo II, nos quais havia crescimento ósseo exuberante sobre a placa. Também em todos foi observado ausência de crepitação e mobilidade no foco de osteotomia, assim como os parafusos bicorticais estavam firmes e posicionados nos orifícios correspondentes. Contudo, algumas diferenças foram observadas entre os grupos. Nos animais do grupo I estava presente calo ósseo discreto (fig. $8 \mathrm{~A}$ ), crescimento ósseo sobre a placa e nos orifícios com ausência dos parafusos. $O$ córtex ósseo sob a placa mostrava coloração branco-avermelhada em todos os animais deste grupo (fig. $8 \mathrm{~A} \mathrm{e}$ B), sugerindo vascularização do periósteo (Mckibbin, 1978; Perren et al., 1991; Hulse e Aron, 1994; Kowalski et al., 1996; Palmer, 1999).

No grupo II o aspecto do córtex sob a placa era de coloração esbranquiçada (fig. 8B), em decorrência de maior pressão da placa sobre 0 periósteo, comprometendo a vascularização local (Rhinelander 1968); Perren et al., 1988; Peterhofen (1989), Eitel et al. 1990a; 1990b; Perren, 2002).

Houve maior dificuldade na remoção dos implantes dos animais deste grupo, devido ao crescimento ósseo sobre o implante e também nos orifícios dos parafusos.

Ao exame histológico, todos os demais apresentaram completo reparo da osteotomia com continuidade cortical. Apesar de o reparo completo ter sido observado em todos os animais, independentemente do grupo, o tipo de tecido ósseo neoformado no local da osteotomia variou de acordo com o tratamento realizado. No grupo I, havia formação de tecido ósseo mineralizado predominantemente do tipo trabecular (fig. 9), com focos de tecido ósseo osteônico. Os osteócitos mostravam-se volumosos alojados em lacunas alargadas, característica de remodelação intensa e os osteoblastos que revestiam as trabéculas ósseas apresentavam-se cuboidais. O tecido ósseo neoformado não exibia ainda as características do tecido ósseo cortical original.

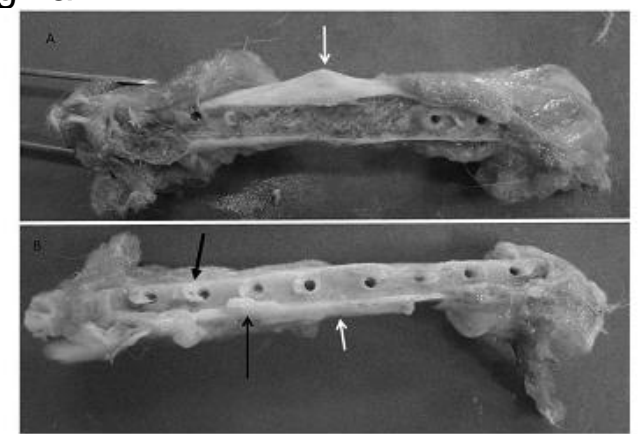

Figura 8- Imagens macroscópicas do fêmur de coelhos, 90 dias após a remoç̃o das placas.

A) Aspecto ósseo após remocão da placa em ponte associada ao pino intramedular: superfície óssea com impressão da placa, tecido avermelhado revestindo a superfície óssea, calo ósseo discreto (seta branca);

B) Aspecto ósseo após remoção da placa de compressão dinâmica: impressão da placa sobre o osso, superfície óssea esbranquiçada e ausência de calo ósseo na região de osteotomia (seta branca), crescimento ósseo sobre a placa (setas pretas).

tecido ósseo mineralizado predominantemente do tipo osteônico com características compatíveis a do tecido ósseo cortical original (fig. 10). Os osteócitos mostravam-se volumosos alojados em lacunas alargadas como característica de remodelação intensa e os osteoblastos apresentam-se cuboidais.

A consolidação de fratura é um notável processo de reparação, porque dele resulta reconstituição do tecido lesado, à sua forma original (McKibbin 1978). Segundo Revell (1983), a quantidade de tecido ósseo, as características micro estruturais, o arranjo espacial, as formas e preservação das conexões ósseas são fatores determinantes para a competência e resistência ósseas. Desta forma, pode-se dizer que os achados histológicos no grupo tratado com a placa de compressão dinâmica mostravam-se superiores àqueles do grupo tratado com placa em ponte, já que no grupo I havia predomínio de tecido ósseo trabecular. A avaliação histológica neste estudo permitiu o conhecimento qualitativo da estrutura 
intramedular e da placa de compressão dinâmica em osteossíntese de fêmur de coelhos

óssea, como descrito por Marino et al. (2003). Tal achado não desqualifica o tratamento biológico com placa em ponte associada ao pino intramedular na fixação de fraturas diafisárias, uma vez que o osso trabecular observado no grupo I é composto de matriz óssea mineralizada que apenas não exibe ainda característica do osso original, mas já é suficientemente capaz de promover estabilização da fratura. Contudo, a remodelação do osso é necessária para se ter um tecido ósseo osteônico de orientação paralela ao eixo longo do osso no espaço da fratura, pois o tecido ósseo primário do calo deve ser reabsorvido e substituído por tecido ósseo lamelar até que a estrutura anterior seja totalmente refeita (Weisbrode, 1995; Remédios, 1999; Rahn, 2002; Junqueira e Carneiro, 2008).

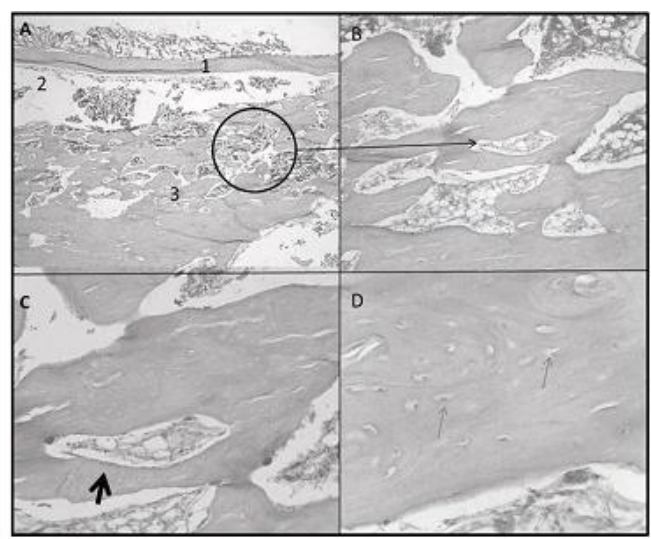

Figura 9- Microfotografia (corte longitudinal), do grupo I 90 dias após fixação da osteotomia com placa em ponte associada ao pino intramedularregião da osteotomia na diáfise femoral de coelhos (HE).

A) 1. Cortical- Ausência de linha de osteotomia, 2 canal medular, 3. Calo ósseo, predomínio tecido ósseo trabecular, pouca quantidade de tecido ósseo osteônico, $5 \mathrm{X}$.

B) Região em detalhe das trabéculas ósseas, cobertura osteoblástica $25 \mathrm{X}$

C) Trabécula em detalhe, seta preta $50 \mathrm{X}$.

D) Tecido ósseo cortical na região da linha de osteotomia, osteócitos em lacunas alargadas (setas), característica de remodelação, 150X

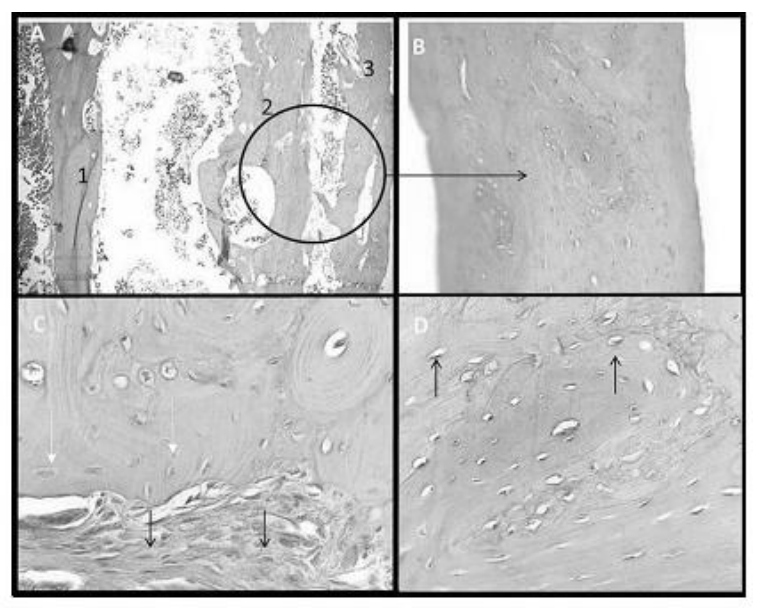

Figura 10- Microfotografia (corte longitudinal) da região da osteotomia na diáfise femoral de coelhos (grupo II- fixação com placa de compressão dinâmica), 90 dias após a cirurgia, $\mathrm{HE}$

A) 1. Cortical sob a placa, 2. cortical oposta a placa e 3. cortical extra (5X); B) Tecido ósseo osteônico, em detalhes, $50 \mathrm{X}$.

C) Tecido ósseo cortical com presença de osteócitos em lacunas alargadas (setas brancas) e periósteo com cobertura osteoblástica (setas pretas), 150X; D) Tecido ósseo cortical, setas indicando osteócito em lacuna alargada, 150X.

\section{CONCLUSÃO}

Sob as condições em que este estudo foi realizado pode-se concluir que: As duas modalidades de fixação conduzem à consolidação dentro do período previsto, mas a fixação com a placa dinâmica de compressão promove maturação precoce do processo em relação à fixação com placa em ponte e, além disto, no período avaliado, a PCD não provocou alteração da constituição óssea, revelando-se melhor método de fixação óssea ao compará-lo ao método da PP.

\section{NOTAS INFORMATIVAS}

Este projeto foi aprovado pelo comitê de ética em experimentação animal da Universidade Federal de Minas Gerais sob protocolo: CETEA $\left(n^{\circ} 034 / 05\right)$.

\section{REFERÊNCIAS}

ARON, D. N.; PALMER, R. H.; JOHNSON, A. L. Biologic strategies and a balanced concept for repair of highly comminuted long bone fractures. Comp Cont Educ Pract. v.17, p. 35-49, 1995. 
BROWN, S. A. Clinical Techniques in Rabbits. Seminars in Av. Ex. Pet Med., v.6, n. 2, p. 8695, 1997.

CHEN, A.L.; JOSEPH, T.N.; WOLINKSY, P.R. et al. Fixation stability of comminuted humeral shaft fractures: locked intramedullary nailing versus plate fixation. J. Trauma, v.53, p.733-71, 1966

EITEL, F.; STEINER, B.; WIELAND, C. et al. Knochensubstanzverlust unterplattenosteosynthese. Hefieunfaltheikd. Injury,v.26, suppl.2, p.36-44, 1990a.

EITEL, F.; HOHN, U.; MATIS, U. et al. Revaskularisierung unter plattenosteosynthesen. Acta Med. Austr., v.17, suppl. 40, p.20-21, 1990b.

FIELD, J.R.; TÖRNKVIST, H. Biological fracture fixation: a perspective. Veterinary

Comparative Orthopaedics and

Traumatology, v.14, n.4, p.169-178, 2001.

GANESH, V.K.; RAMAKRISHMA, K; GHISTA, D.N. Biomechanics of bone-fracture fixation by stiffness-graded plate in comparison with stainless-steel plates. Biomed. Eng. Online, v.2, p.1-15, 2005.

HULSE, D. A.; FERRY, K.; FAWCETT, A. et al. Effect of intramedullary pin size on reducing bone plate strain. Vet Comp Orthop Traumatol, v.13, n.4, p.185-190, 2000.

HULSE, D.A.; HYMAN, W.; NORI, M. et al. Reduction in plate strain by addition of an intramedullary pin. Vet. Surg., v.26, n.6, p.451459, 1997.

HULSE, D.A.; JOHNSON, A.L. Fundamentos de cirurgia ortopédica e tratamento de fraturas In: FOSSUM, T.W. Cirurgia de pequenos animais. São Paulo: Roca, 2002.p.787-853.

JOHNSON, A.L.; SMITH, C.W.; SCHAEFFER, D.J. Fragment reconstruction an bone plate fixation versus bridging plate fixation for treating highly comminuted femoral fractures in dogs: 35 cases (1987-1997). J Am Vet Med Assocv., v.213, p1157-1161, 1998.

JUNQUEIRA, L.C.; CARNEIRO, J. Tecido ósseo: Histologia básica. 11ed.. Rio de Janeiro: Guanabara Koogan, 2008, 524 p.

KOWALSKI, M.JH.; SCHEMITSCH, H.E.; HARRINGTON, R.M. iet al. A comparative biomechamical avaluation of a moncontacting plate and currently used devices for tibial fixation. J. trauma: ing. Infec. critical care. v.40, n.1, p.5-9, 1996.
MARINO, J.A.M. Efeito do laser terapêutico de baixa potência sobre o processo de reparação óssea em tíbia de rato. 2003. 106f. Dissertação (Mestrado). Centro de Ciências Biológicas e da Saúde, Universidade Federal de São Carlos.

MCKIBBIN, B. The biology of fracture healing in long bones. J Bone Joint Surg, v.60, p.150162, 1978.

MICLAU, T.; MARTIN, R.E. The evolution of modern plate osteosynthesis. Injury,v.28, Suppl.1, p.S-A3-S-A6, 1997.

MODABBER, M.R.; JUPITER, J.B. Operative management of diaphyseal fractures of the humerus. Plate versus nail. Clin Orthop Relat Res., v.347, p. 93-104, 1998.

OSÓRIO, L.; OSÓRIO, E.G. \& AMARAL, F.G. Tratamento das fraturas cominutivas o fêmur pelo método da placa em ponte. Rev Bras Ortop, v.29, p.855-860, 1994.

PALMER, R.E. Biological osteosynthesis. Vet. Clinics North Am. Small Anim. Practice, v.29, n.5, p.1171-1185, 1999.

PERMATTEI, D.L.; FLO,G.; DECAMP, C. Handbook of small animal orthopedics and fracture repair. 3ed. Philadelphia. W. B. Saunders, 2006, 24-146.

PERREN, S.M Evolution of the internal fixation of long bone fractures. J Bone Joint Surg, v.84b, n.8, p.1093-1110, 2002.

PERREN, S.M.; Z`BRUN, P. Shortcomings of conventional plate design. In: PERREN, S.M., ALLGOWER, M., BURGH, H.B. et al. The concept of biological plating using the limited contact dynamic compression plate (LC-DCP). Injury, v.22, Supl.1, p.1-41, 1991.

PERREN, S.M.; CORDY, B.; RAHN, A. et al. Early temporary porosis of bone induced by internalfixation implants. A reaction to necrosis, not to stress protection? Clinic Orthop., n.232, p.139-151, 1988.

PETERHOFEN, K.S. Knochenumbau unter plattenosteosynthesis ben hund. Disse. Med. Vet., Munchen, 1989.

REEMS, M.R.; BEALE, B.S.; HULSE, D.A. Use of a plate-rod construct and principles of biological osteosynthesis for repair of diaphyseal fractures in dogs and cats: 47 cases (19942001), J Am Vet. Med Assoc, v.223, p.330-335, 2003.

REMÉDIOS, A. Bone and Healing. Vet. Clin. north Am,v.29, n.5, p.1028-1041, 1999. 
REVELL, P.A. Histophometry of bone. J Clin

Pathol. v.36, n.12, p.1323-1331, 1983.

RAHN, B.A. Bone healing : histological and physiological concepts. In: Bone in clinical orthopedics. Carter, D.R et al.. (ed1). Editors: Summer-smith, G; Fackelman, G.E. p. 287-325, 2002. AO-publishing. Stuttgart, Germany, 2002

RHINELANDER, F.W. Microangiography in Bone Healing: I. Undisplaced Closed Fractures. Bone Joint Surg Am, v.44, p.1273-1298, 1962.

RHINELANDER, F.W. The normal microcirculation of diaphyseal córtex ant its response to fracture. J. Bone Joint Surg. (Am), v.50A, p.784-800, 1968.

SHIMABUKURO, E.H.; TUCCI, P.F.; REIS, F.B et al. Estudo comparativo do da placa-ponte $\mathrm{e}$ da haste intramedular bloqueada nas fraturas diafisárias cominutivas emprego do fêmur. Rev Bras Ortop, v.32, n.3, 1997.

UHTHOFF, H.K.; POITRAS,P.; BACKMAN, D. Internal plate fixation of fractures: shorthistory and recent developments. J Orthop Sci. v.11, p.118-126, 2006.

VASCONCELOS, J. W.; M.; PORTO, L. C.K. Tratamento das fraturas cominutivas do fêmur com a utilização da placa em ponte. Rev Bras Ortop, v.39, n.8, p.415-422, 2004.

WEISBRODE, SE. Function, Strucuture, and Healing of the Musculoskeletal System. In: OLMSTEAD, ML: Small Animal Orthopedics. Mosby-Year Book Inc., Missouri, 1995 p.42-47.

YUEHUEI H.; FRIEDMAN, R. J. Animal models in orthopaedic research, CRC Press, p.208, 1999. 217p. 